\title{
Optimal Irrigation Planning and Operation of Multi Objective Reservoir Using Fuzzy Logic
}

\author{
Jyotiba B. Gurav \\ Department of Civil Engineering, Amrutvahini College of Engineering, Sangamner, India \\ Email: jyotiba.gurav@rediffmail.com
}

Received 10 December 2015; accepted 21 February 2016; published 24 February 2016

Copyright (C) 2016 by author and Scientific Research Publishing Inc.

This work is licensed under the Creative Commons Attribution International License (CC BY). http://creativecommons.org/licenses/by/4.0/

(c) (i) Open Access

\section{Abstract}

In the present study the MOFLP models have been developed for the optimal cropping pattern planning which maximizes the four objectives such as Net Benefits (NB), Crop Production (CP), Employment Generation (EG) and Manure Utilization (MU) under conflicting situation and also, for maximization of Releases for Irrigation (RI) and Releases for Power (RP) simultaneously under uncertainty by considering the fuzziness in the objective functions. The developed models have been applied using the LINGO 13 (Language for Interactive General Optimization) optimization software to the case study of the Jayakwadi Project Stage-II across Sindhphana River, in the State of Maharashtra India. The various constraints have been taken into consideration like sowing area, affinity to crop, labour availability, manure availability, water availability for optimal cropping pattern planning. Similarly constraints to find the optimal reservoir operating policy are releases for power and turbine capacity, irrigation demand, reservoir storage capacity, reservoir storage continuity. The level of satisfaction for a compromised solution of optimal cropping pattern planning for four conflicting objectives under fuzzy environment is worked out to be $\lambda=0.68$. The MOFLP compromised solution provides NB $=1088.46$ (Million Rupees), $\mathrm{CP}=241003$ (Tons), $\mathrm{EG}=$ 23.13 (Million Man days) and $\mathrm{MU}=111454.70$ (Tons) respectively. The compromised solution for optimal operation of multi objective reservoir yields the level of satisfaction $(\lambda)=0.533$ for maximizing the releases for irrigation and power simultaneously by satisfying the constraint of the system under consideration. The compromised solution provides the optimal releases, i.e. $\mathbf{R I}=$ $348.670 \mathrm{Mm}^{3}$ and $\mathrm{RP}=234.285 \mathrm{Mm}^{3}$ respectively.

\section{Keywords}

Irrigation Planning, Reservoir Operation, Uncertainty, Multi Objective Fuzzy Linear Programming 


\section{Introduction}

Irrigation planning objectives associated with uncertainty are conflicting and especially in developing countries like India, there are many objectives related to irrigation planning and reservoir operation that must simultaneously be satisfied. Therefore, irrigation planning with uncertainty to find optimal cropping patterns and to derive the optimal releases of reservoir operation, has thus studied in multi objective framework under fuzzy environment so that suitable and sustainable strategies can be developed for practical implementation.

The LP irrigation planning model has been developed for evaluation of irrigation development strategy for the case study of the Sri Ram Sagar project in the State of Andhra Pradesh, India. The uncertainty in inflows arising out of the uncertainty in the rainfall is tackled through chance constrained (stochastic) programming [1]. Raju and Nagesh Kumar [2] formulated the Fuzzy Linear Programming (FLP) for three conflicting objectives and dealt with fuzzification of objective functions. Raju and Duckstein [3] developed the MOFLP model for sustainable irrigation planning, considering only the objectives fuzzy in nature. Regulwar and Anand Raj [4] developed a monthly Multi Objective Genetic Algorithm Fuzzy Optimization model and it has applied to a multireservoir system in the Godavari river sub basin in the State of Maharashtra, India. Regulwar and Kamodkar [5] have focused on the derivation of multipurpose single reservoir release policies with fuzzy constraints. Regulwar and Gurav [6]-[10] and Gurav and Regulwar [11] [12] have presented the irrigation planning under uncertainty using multi objective fuzzy linear programming approach. Kamodkar and Regulwar [13]-[15] have presented the study of multiobjective single reservoir operation model focused with the uncertainty associated with releases for irrigation and hydropower and applied same to the Jayakwadi project stage-II in the State of Maharashtra, India.

In the literature presented, it has found that the no model has been formulated for the multi objective sustainable irrigation planning and reservoir operation with Fuzzification of the objective functions to the case study of the Jayakwadi reservoir project stage-II. The objectives of the present study are to develop the model for optimal cropping pattern planning under fuzzy environment and also to develop model for optimal operating policies in a multiple crop, multiple criterion environment, on a reservoir in a river sub basin.

\section{Methodology and Model Development}

\subsection{Description of the Case Study Area}

The salient features of the Jayakwadi Project Stage-II have shown in the following Table 1 . Figure 1 shows an index map of Jayakwadi project, State of Maharashtra, India.

\subsection{Model Development for Cropping Pattern Planning}

The objective is to find out the optimal cropping pattern for 75\% dependable yield in command area. The problem has been formulated as an optimization model based on deterministic inflows.

\subsection{Objective Function}

The following four objectives for irrigation planning have been considered in the present study.

Table 1. Salient features of the Jayakwadi project stage-II.

\begin{tabular}{|c|c|c|}
\hline Sr. No. & Particular & Quantity \\
\hline 1 & Gross Capacity at F. R. L. & $453.64 \mathrm{Mm}^{3}$ \\
\hline 2 & Capacity of Dead Storage & $142.34 \mathrm{Mm}^{3}$ \\
\hline 3 & Capacity of Live Storage & $311.30 \mathrm{Mm}^{3}$ \\
\hline 4 & Capacity for Power Generation & $2.25 \mathrm{MW}$ \\
\hline 5 & No. of Turbines & $3 \times 750 \mathrm{KW}$ \\
\hline 6 & Irrigable Command Area & $938.85 \mathrm{Km}^{2}$ \\
\hline
\end{tabular}




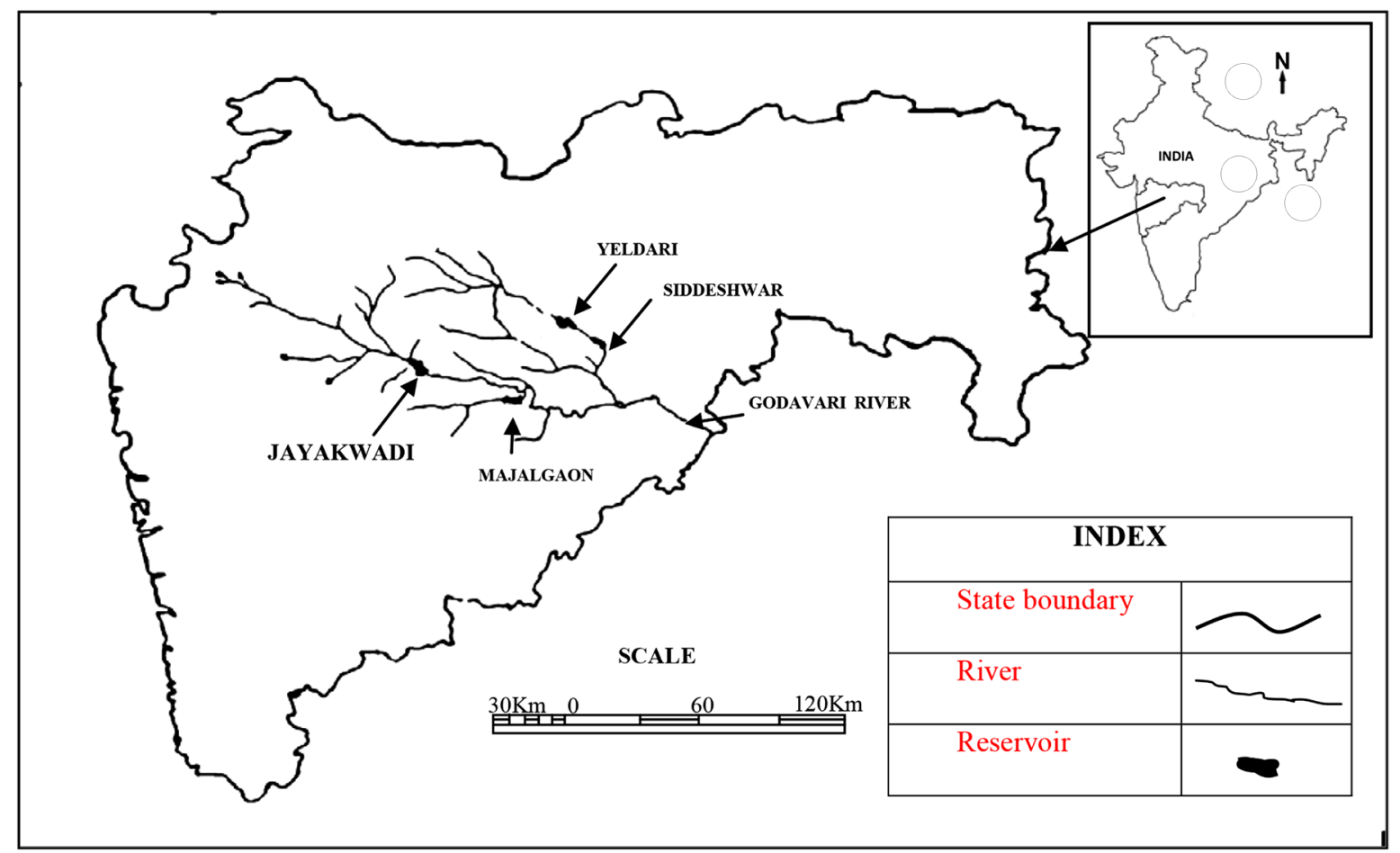

Figure 1. Index map of Jayakwadi project, state of Maharashtra, India.

\subsection{Maximization of Net Benefits (NB)}

Maximization of Net benefits can be expressed as:

$$
\begin{aligned}
\text { Maximize } N B= & {\left[\left(\sum_{i=1}^{K_{1}} A_{i}^{K}+\sum_{i=1}^{R_{1}} A_{i}^{R}+\sum_{i=1}^{T_{1}} A_{i}^{T S}+\sum_{i=1}^{P_{1}} A_{i}^{P}+\sum_{i=1}^{H_{1}} A_{i}^{H W}\right) B C_{i}\right.} \\
& \left.-\left(\sum_{i=1}^{K_{1}} A_{i}^{K}+\sum_{i=1}^{R_{1}} A_{i}^{R}+\sum_{i=1}^{T_{1}} A_{i}^{T S}+\sum_{i=1}^{P_{1}} A_{i}^{P}+\sum_{i=1}^{H_{1}} A_{i}^{H W}\right) I C_{i}\right]
\end{aligned}
$$

[In which $i=$ crop index. $1=$ Sugarcane (P), $2=$ Banana (P), $3=$ Chilies (TS), $4=$ L S Cotton (TS), 5 = Sorghum $(\mathrm{K}), 6=$ Paddy $(\mathrm{K}), 7=$ Sorghum $(\mathrm{R}), 8=$ Wheat $(\mathrm{R}), 9=\mathrm{Gram}(\mathrm{R})$ and $10=$ Groundnut $(\mathrm{HW})$ and ha $=$ $\left.10000 \mathrm{~m}^{2}\right]$

$A_{i}^{K}=$ Area of $i^{\text {th }}$ crop in kharif season (ha); $\quad A_{i}^{R}=$ Area of $i^{\text {th }}$ crop in rabi season (ha);

$A_{i}^{T S}=$ Area under two seasonal crops in (ha); $A_{i}^{P}=$ Area under perennial crop in (ha);

$A_{i}^{H W}=$ Area under hot weather crop in (ha); $B C_{i}=$ Benefit coefficient for $i^{\text {th }}$ Crop;

$I C_{i}=$ Input cost for $i^{\text {th }}$ Crop;

$P_{1}=$ Perennial crops;

$P$ = Perennial;

$T_{1}=$ Two seasonal crops;

$K_{1}=$ Crops under Kharif season;

TS = Two seasonal;

$R_{1}=$ Crops under Rabi season;

$K=$ Kharif;

$R=$ Rabi;

$H_{1}=$ Hot weather crops.

$H W=$ Hot weather;

The Net Benefits coefficients (NB) from the irrigated area under various crops are obtained by subtracting the input cost (20\% of gross benefit) from gross benefit for different crops. The Gross benefits are calculated by multiplying the average yield of a crop per ha and current market price of that crop. The Crop Production (CP) coefficients are taken as the average yield of a crop per ha [16].

\subsection{Maximization of Crop Production (CP)}

The crop production is maximized and can be expressed as: 


$$
\operatorname{Maximize}(C P)=\left[\left(\sum_{i=1}^{K_{1}} A_{i}^{K}+\sum_{i=1}^{R_{1}} A_{i}^{R}+\sum_{i=1}^{T_{1}} A_{i}^{T S}+\sum_{i=1}^{P_{1}} A_{i}^{P}+\sum_{i=1}^{H_{1}} A_{i}^{H W}\right) A Y_{i}\right]
$$

$A Y_{i}=$ Average yield of $i^{\text {th }}$ crop.

\subsection{Maximization of Employment Generation (EG)}

Keeping in mind the socioeconomic development, the policy maker has to concentrate on the maximization of employment generation or labour availability.

$$
\operatorname{Maximize}(E G)=\left[\left(\sum_{i=1}^{K_{1}} A_{i}^{K}+\sum_{i=1}^{R_{1}} A_{i}^{R}+\sum_{i=1}^{T_{1}} A_{i}^{T S}+\sum_{i=1}^{P_{1}} A_{i}^{P}+\sum_{i=1}^{H_{1}} A_{i}^{H W}\right) M D_{i}\right]
$$

$M D_{i}=$ Number of man days for $i^{\text {th }}$ crop per ha.

The requirement of labour or numbers of Man Days (MD) for a particular crop per ha is considered through discussion with farmers and experts from agricultural fields.

\subsection{Maximization of Manure Utilization (MU)}

In order to maintain the fertility and nutrient sufficiency of soil in a proper manner, one should concentrate on the maximization of the use of manures.

$$
\operatorname{Maximize}(M U)=\left[\left(\sum_{i=1}^{K_{1}} A_{i}^{K}+\sum_{i=1}^{R_{1}} A_{i}^{R}+\sum_{i=1}^{T_{1}} A_{i}^{T S}+\sum_{i=1}^{P_{1}} A_{i}^{P}+\sum_{i=1}^{H_{1}} A_{i}^{H W}\right) M U_{i}\right]
$$

$M U_{i}=$ Requirement/Utilization of manure in tons for $i^{\text {th }}$ crop per ha.

The Requirement of Manure (MU) for a crop per ha is considered through discussion with farmers and experts from agricultural fields.

\subsection{Constraints}

The above four objectives are subject to the various constraints like total sowing area, maximum sowing area, affinity to particular crops, labour availability, manure availability, water availability and non-negativity (The details are not given due to space limitation).

\subsection{Model Development for Reservoir Operation}

The two objective functions are considered for the present case study, which are:

1) Maximization of irrigation releases (i.e. RI)

$$
\text { Maximize } z=\sum_{t=1}^{12}(R I)_{i t}
$$

2) Maximization of hydropower releases (i.e. RP)

$$
\text { Maximize } z=\sum_{t=1}^{12}(R P)_{i t}
$$

\subsection{Constraints}

The above two objectives are subject to the various constraints like Releases for Power, Turbine Capacity, Irrigation Demand, Reservoir Storage-Capacity, and Reservoir Storage Continuity Constraint (The details are not given due to space limitation).

\subsection{Algorithm for Fuzzy Linear Programming with Fuzzy Objective Functions ( $\tilde{Z}$ )}

The Fuzzy Linear Programming (FLP) Algorithm for fuzzy objectives has divided into the following steps:

1) Considering only one objective at a time and solve the problem as a linear programming problem. 
2) Focusing on the results obtained in the step 1, work out the corresponding values of each objective from the solution obtained.

3) Comparing the values of objective function obtained in step 2; find out $\left(\mathrm{Z}_{U}\right)$ and $\left(\mathrm{Z}_{\mathrm{L}}\right)$ for each objective under consideration.

4) Keeping in view the values of $\left(\mathrm{Z}_{U}\right)$ and $\left(\mathrm{Z}_{\mathrm{L}}\right)$ for each objective; establish the linear membership function.

5 ) Introducing the dummy variable $(\lambda)$, now the objective function changes to maximize the dummy variable $(\lambda)$ subjected to the additional constraints due to the fuzziness in the value of the objective functions and original constraints.

6) Develop the equivalent Linear Programming (LP) model as a Multi Objective Fuzzy Linear Programming (MOFLP) model.

7) Work out compromised solution with the level of satisfaction $(\lambda)$.

\subsection{Fuzzy Linear Programming}

The most general type of fuzzy linear programming is formulated as follows:

$$
\begin{array}{ll}
\max \sum_{j=1}^{n} C_{j} X_{j} & \\
\text { S.t. } \sum_{j=1}^{n} A_{i j} X_{j} \leq B_{i} & \left(i \in \mathbb{N}_{m}\right) \\
X_{j} \geq 0 & \left(j \in \mathbb{N}_{n}\right)
\end{array}
$$

where $A_{i j}, B_{i}, C_{j}$ are fuzzy numbers, and $X_{j}$ are variables whose states are fuzzy numbers $\left(i \in \mathbb{N}_{m}, j \in \mathbb{N}_{n}\right)$; the operations of addition and multiplication are operations of fuzzy arithmetic, and $\leq$ denotes the ordering of fuzzy numbers [17].

\section{Results and Discussion}

In the present study the MOFLP models have been developed for the optimal cropping pattern planning which maximizes the four objectives such as NB, CP, EG and MU under conflicting situation and also, for maximization of RI and RP simultaneously under uncertainty by considering the fuzziness in the objective functions. The developed models have been applied to the case study of the Jayakwadi project stage-II across the Sindhphana River near Majalgaon town.

The objective functions of the present study considering the Equations (1)-(4) of the Linear Programming Planning (LPP) model, which are the maximization of the NB, CP, EG and MU for the command area of the Jayakwadi Project Stage-II. These objective functions are maximized separately subjected to constraints using the LINGO 13 (Language for INteractive General Optimization) optimization software. The results of this individual maximization of the four different objectives are used to construct the linear membership function for each objective taking the help of the best $(+)$ and worst $(-)$ value of the same. The membership functions are shown graphically in Figures 2-5.

The same membership functions are written in the form of mathematical Equations (7)-(10).

$$
\begin{aligned}
& \mu_{z_{1}}(x)=\left\{\begin{array}{lc}
1 & z_{1} \geq 1180.33 \\
\frac{\left(z_{1}-892.76\right)}{(1180.33-892.76)} & 892.76<z_{1}<1180.33 \\
0 & z_{1} \leq 892.76
\end{array}\right. \\
& \mu_{z_{2}}(x)=\left\{\begin{array}{lr}
1 & z_{2} \geq 315610.80 \\
\frac{\left(z_{2}-77762.07\right)}{(315610.80-77762.07)} & 77762.07<z_{2}<315610.80 \\
0 & z_{2} \leq 77762.07
\end{array}\right.
\end{aligned}
$$




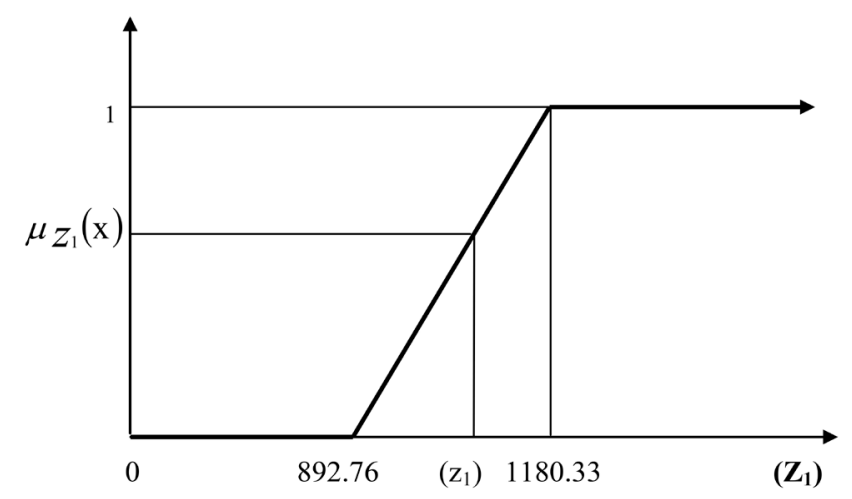

Figure 2. Membership function for $Z_{1}$ (Million rupees).

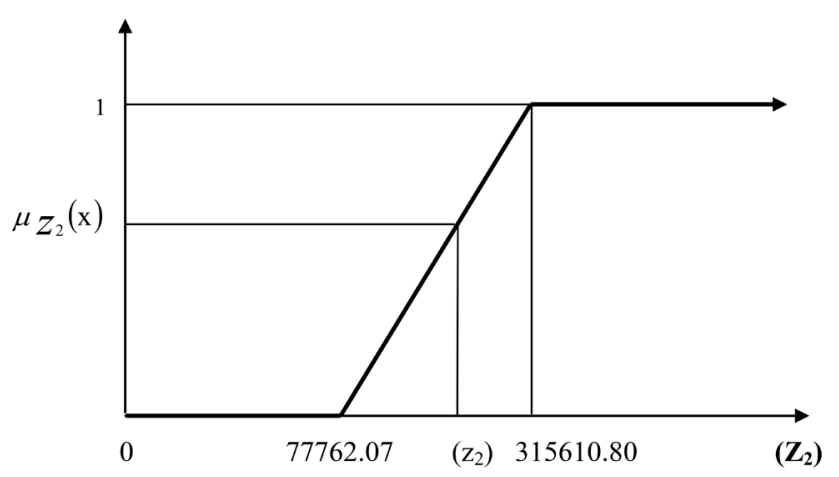

Figure 3. Membership function for $Z_{2}$ (Tons).

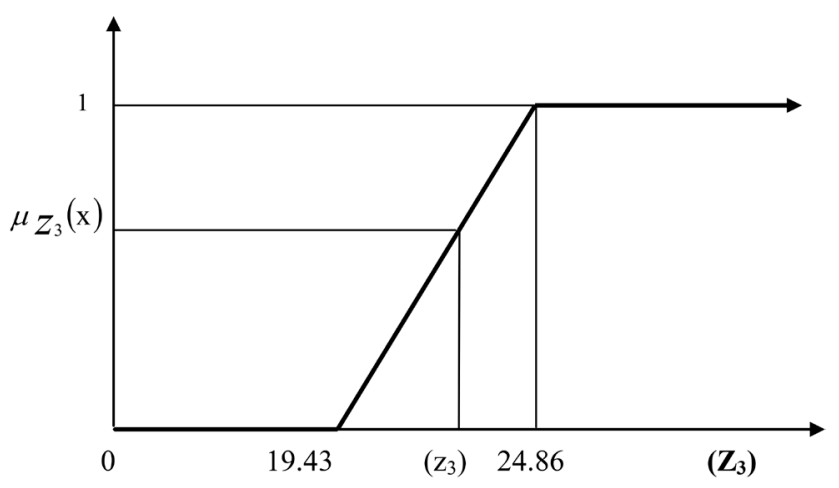

Figure 4. Membership function for $Z_{3}$ (Million man days).

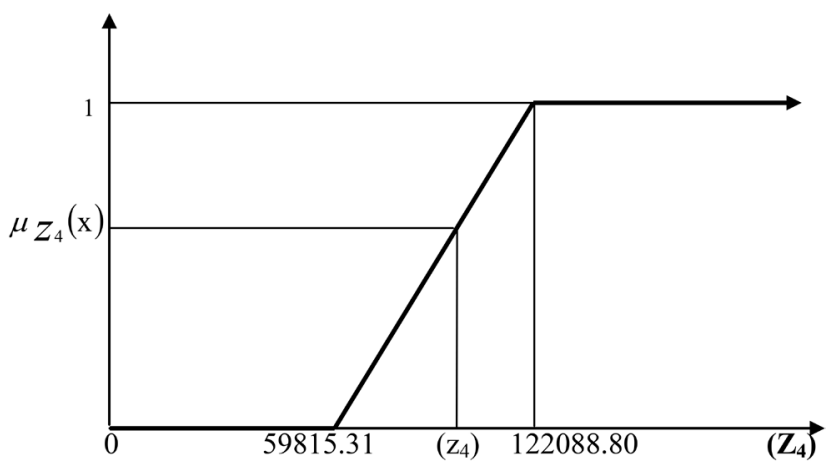

Figure 5. Membership function for $Z_{4}$ (Tons). 


$$
\begin{aligned}
& \mu_{z_{3}}(x)=\left\{\begin{array}{lc}
1 & z_{3} \geq 24.86 \\
\frac{\left(z_{3}-19.43\right)}{(24.86-19.43)} & 19.43<z_{3}<24.86 \\
0 & z_{3} \leq 19.43
\end{array}\right. \\
& \mu_{z_{4}}(x)=\left\{\begin{array}{lc}
1 & z_{4} \geq 122088.80 \\
\frac{\left(z_{4}-59815.31\right)}{(122088.80-59815.31)} & 59815.31<z_{4}<122088.80 \\
0 & z_{4} \leq 59815.31
\end{array}\right.
\end{aligned}
$$

The results are shown in Table 2. The membership functions $\mu_{1}(X), \mu_{2}(X), \mu_{3}(X)$ and $\mu_{4}(X)$ of the fuzzy sets characterizing the objective functions rise linearly from 0 to 1 at the highest achievable value of $Z_{1}=1180.33$ Million Rs, $Z_{2}=315610.80$ Tons, $Z_{3}=24.86$ Million Man days and $Z_{4}=122088.80$ Tons respectively. The level of satisfaction associated with NB rises from 0 if the NB is 892.76 Million Rs or less to 1 if the total NB is $Z_{1}=$ 1180.33 Million Rs or more. The level of satisfaction with respect to CP rises from 0 if the CP is 77762.07 Tons or less to 1 if the CP is $Z_{2}=315610.80$ Tons or more and the satisfaction level associated with EG rises from 0 for 19.43 Million Man days or less to 1 for EG $Z_{3}=24.86$ Million Man days and more.

\begin{tabular}{|c|c|c|c|c|c|c|}
\hline \multirow{2}{*}{ S. N. } & \multirow{2}{*}{ Crop and Season } & \multicolumn{4}{|c|}{ Solution for Maximization of } & \multirow{2}{*}{$\begin{array}{c}\text { Compromised } \\
\text { Solution }(\lambda=\mathbf{0 . 6 8 0}) \\
\text { Area of Crop (ha) }\end{array}$} \\
\hline & & NB $\left(Z_{1}\right)$ (ha) & CP $\left(Z_{2}\right)$ (ha) & EG ( $\left.Z_{3}\right)$ (ha) & MU $\left(Z_{4}\right)$ (ha) & \\
\hline 1 & Sugarcane (P) & 2750 & 2750 & 0 & 2750 & 1758.90 \\
\hline 2 & Banana (P) & 1375 & 1375 & 0 & 1375 & 1375 \\
\hline 3 & Chilies (TS) & 2750 & 2750 & 2750 & 2750 & 2750 \\
\hline 4 & L S Cotton (TS) & 0 & 0 & 22895 & 22895 & 21026.67 \\
\hline 5 & Sorghum (K) & 10996 & 10996 & 10996 & 10996 & 10996 \\
\hline 6 & Paddy (K) & 9158 & 9158 & 9158 & 9157.20 & 9158 \\
\hline 7 & Sorghum (R) & 12013.49 & 13737 & 13737 & 13737 & 0 \\
\hline 8 & Wheat (R) & 22895 & 22895 & 22895 & 9481.37 & 22895 \\
\hline 9 & Gram (R) & 4579 & 2774.70 & 4579 & 0 & 4579 \\
\hline 10 & Groundnut (HW) & 0 & 0 & 1368.03 & 2750 & 0 \\
\hline \multicolumn{2}{|c|}{ Net Cropped Area (На) } & 66516.49 & 66435.70 & 88378.03 & 75891.57 & 74538.57 \\
\hline
\end{tabular}

Table 2. Solution for the NB, CP, EG and MU by LPP and MOFLP model.

NB: $Z_{1}=1180.33$ ( $Z_{1}^{+}$) (Million Rs); $Z_{2}=315448.20$ (Tons); $Z_{3}=19.54$ (Million Man Days); $Z_{4}=59642.34$ (Tons); Irrigation Intensity $(\%)=70.85$

CP: $Z_{1}=1175.63$ (Million Rs); $Z_{2}=315610.80$ ( $Z_{2}^{+}$) (Tons); $Z_{3}=19.43$ ( $Z_{3}^{-}$) (Million Man Days); $Z_{4}=59815.31$ ( $Z_{4}^{-}$) (Tons); Irrigation Intensity $(\%)=70.76$

EG: $Z_{1}=892.76$ ( $Z_{1}^{-}$) (Million Rs); $Z_{2}=77762.07$ ( $Z_{2}^{-}$) (Tons); $Z_{3}=24.86$ ( $Z_{3}^{+}$) (Million Man Days); $Z_{4}=108995.10$ (Tons); Irrigation Intensity $(\%)=94.13$

MU: $Z_{1}=1059.16$ (Million Rs); $Z_{2}=300763.20$ (Tons); $Z_{3}=20.82$ (Million Man Days); $Z_{4}=122088.80$ ( $Z_{4}^{+}$) (Tons);

Irrigation Intensity $(\%)=80.83$

Compromised Solution: $Z_{1}=1088.46$ (Million Rs); $Z_{2}=241003$ (Tons); $Z_{3}=23.13$ (Million Man Days); $Z_{4}=111454.70$ (Tons);

Irrigation Intensity (\%) = 79.40

(+ve is the best value/aspired level of objective and -ve is the worst value/lowest acceptable level of objective). 
Similarly, the level of satisfaction associated with MU rises from 0 if the MU is 59815.31 Tons or less to 1 if the MU is $Z_{4}=122088.80$ Tons or more. The maximum satisfaction level of the membership functions of four participating/conflicting objectives has been designated as the 'best' achieved/compromised solution. Finally the modified form of the optimization problem (MOFLP) by introducing the dummy variable $\lambda=\min \left[\mu_{1}(X), \mu_{2}(X)\right.$, $\left.\mu_{3}(X), \mu_{4}(X)\right]$ such that the objective is to:

$$
\begin{gathered}
\text { Maximize } \lambda \\
\text { Subject to, }
\end{gathered}
$$

and all other original constraint given in the model; $\lambda \geq 0$. The solution of MOFLP model is presented in Table 2 . From this solution, it is observed that the area to be irrigated is constant in case of Chilies (TS), Sorghum (K) and Paddy (K) under LP model and MOFLP model solution. When the NB is to be maximized, then the area under irrigation is zero for LS Cotton (TS) and Groundnut (HW) because the benefit coefficient is low for these crops. Similarly, when the Crop Production is to be maximized, then the area under irrigation is zero for LS Cotton (TS) and Groundnut (HW).

Also, when the EG is to be maximized, then the area under irrigation is zero for Sugarcane (P), Banana (P). This is due to the labour requirement per ha is low and also due to the limited area under the existing cropping pattern. On the other hand, when MU is to be maximized, then the area under irrigation is zero for Gram (R) as manure requirement per ha is low and also due to the limited area under the existing cropping pattern. The area under irrigation is zero for Sorghum (R) and Groundnut (HW) if four conflicting objectives are considered simultaneously under MOFLP environment. In case of individual optimization for four objectives separately the irrigation intensity is $70.85 \%, 70.76 \%, 94.13 \%$ and $80.83 \%$ respectively, while in case of MOFLP it is $79.40 \%$.

In case of MOFLP the irrigation intensity is more by $8.55 \%, 8.64 \%, 1.21 \%$ if we compare with individual optimization for net benefits and crop production respectively, and less by $14.73 \%$ and $1.43 \%$ if we compare with individual optimization for employment generation and manure utilization respectively.

The level of satisfaction for a compromised solution for four conflicting objectives under fuzzy environment is works out to be $\lambda=0.68$. The MOFLP compromised solution provides NB $=1088.46$ (Million Rupees), $\mathrm{CP}=$ 241003 (Tons), $\mathrm{EG}=23.13$ (Million Man days) and MU = 111454.70 (Tons) respectively.

The results of this individual maximization of the two different objectives are used to construct the linear membership function for each objective taking the help of the best $(+)$ and worst $(-)$ value of the same. The membership functions are shown graphically in Figure 6 and Figure 7 . The same membership functions are written in the form of mathematical Equations (11-12). The results are shown in Table 3.

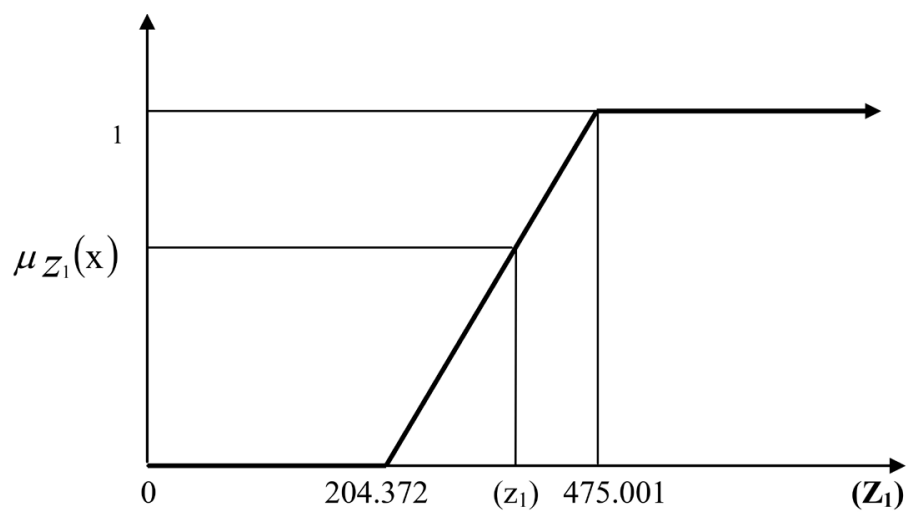

Figure 6. Membership function for $Z_{1}\left(\mathrm{Mm}^{3}\right)$. 


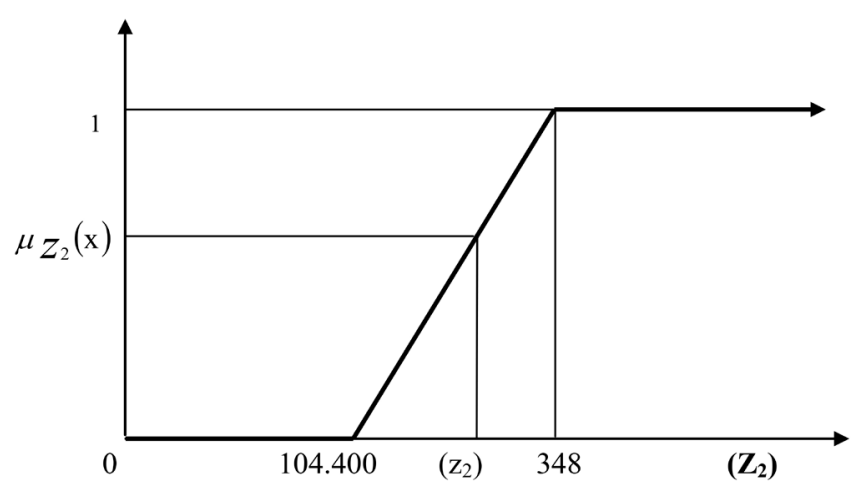

Figure 7. Membership function for $Z_{2}\left(\mathrm{Mm}^{3}\right)$.

Table 3. Solution for maximization of RI and RP by LPP and MOFLP model.

\begin{tabular}{|c|c|c|c|c|c|c|c|}
\hline \multirow{2}{*}{ S. $\mathbf{N}$. } & \multirow{2}{*}{ Month } & \multicolumn{4}{|c|}{ Solution for Maximization of Releases $\left(\mathrm{Mm}^{3}\right)$} & \multicolumn{2}{|c|}{ Compromised Solution $(\lambda=\mathbf{0 . 5 3 3})$} \\
\hline & & RI & $\mathbf{R P}$ & RI & $\mathbf{R P}$ & $\mathbf{R I}\left(\mathbf{M m}^{3}\right)$ & $\mathbf{R P}\left(\mathbf{M m}^{3}\right)$ \\
\hline 1 & June & 2.929 & 8.700 & 2.136 & 29.000 & 2.136 & 9.493 \\
\hline 2 & July & 20.830 & 8.700 & 6.249 & 29.000 & 6.249 & 27.960 \\
\hline 3 & August & 37.640 & 8.700 & 11.292 & 29.000 & 37.640 & 29.000 \\
\hline 4 & September & 46.020 & 8.700 & 13.806 & 29.000 & 46.020 & 29.000 \\
\hline 5 & October & 132.010 & 8.700 & 39.603 & 29.000 & 125.339 & 29.000 \\
\hline 6 & November & 127.050 & 8.700 & 38.115 & 29.000 & 38.115 & 29.000 \\
\hline 7 & December & 42.180 & 8.700 & 26.829 & 29.000 & 26.829 & 29.000 \\
\hline 8 & January & 30.204 & 8.700 & 30.204 & 29.000 & 30.024 & 17.032 \\
\hline 9 & February & 9.006 & 8.700 & 9.006 & 29.000 & 9.006 & 8.700 \\
\hline 10 & March & 8.694 & 8.700 & 8.694 & 29.000 & 8.694 & 8.700 \\
\hline 11 & April & 10.674 & 8.700 & 10.674 & 29.000 & 10.674 & 8.700 \\
\hline 12 & May & 7.764 & 8.700 & 7.764 & 29.000 & 7.764 & 8.700 \\
\hline & Total & $475.001\left(\mathrm{Z}_{1 \mathrm{Max}}\right)$ & $104.400\left(Z_{2 M i n}\right)$ & $204.372\left(\mathrm{Z}_{1 \mathrm{Min}}\right)$ & $348.000\left(Z_{2 \operatorname{Max}}\right)$ & 348.670 & 234.285 \\
\hline
\end{tabular}

$$
\begin{aligned}
& \mu_{z_{1}}(x)=\left\{\begin{array}{lc}
1 & z_{1} \geq 475.001 \\
\frac{\left(z_{1}-204.372\right)}{(475.001-204.372)} & 204.372<z_{1}<475.001 \\
0 & z_{1} \leq 204.372
\end{array}\right. \\
& \mu_{z_{2}}(x)=\left\{\begin{array}{lc}
1 & z_{2} \geq 348 \\
\frac{\left(z_{2}-104.400\right)}{(348-104.400)} & 104.400<z_{2}<348 \\
0 & z_{2} \leq 104.400
\end{array}\right.
\end{aligned}
$$

The membership functions $\mu_{1}(X)$, and $\mu_{2}(X)$ of the fuzzy sets characterizing the objective functions rise linearly from 0 to 1 at the highest achievable value of $Z_{1}=475.001 \mathrm{Mm}^{3}$ and $Z_{2}=348.00 \mathrm{Mm}^{3}$ respectively. The level of satisfaction associated with RI rises from 0 if the RI is $204.372 \mathrm{Mm}^{3}$ or less to 1 if the total RI is $Z_{1}=$ 475.001 $\mathrm{Mm}^{3}$ or more. The level of satisfaction with respect to RP rises from 0 if the RP is $104.400 \mathrm{Mm}^{3}$ or less 
to 1 if the RP is $Z_{2}=348 \mathrm{Mm}^{3}$ or more. The maximum level of satisfaction from the membership functions of two participating/conflicting objectives has been designated as the 'best' achieved/compromised solution.

The other main objective functions of the present study considering the Equations (5), (6) of the LPP model, which are the maximization of the releases for irrigation and releases for hydropower of the Jayakwadi Project Stage-II. These objective functions are maximized separately subjected to constraints using the LINGO 13 (Language for INteractive General Optimization) optimization software. Finally the modified form of the optimization problem (MOFLP) by introducing the dummy variable $\lambda=\min \left[\mu_{1}(X), \mu_{2}(X)\right.$,] such that the objective is to:

$$
\begin{gathered}
\text { Maximize } \lambda \\
\text { Subject to } \\
\left(Z_{1}-204.372 \times 10^{6}\right) /\left(475.001 \times 10^{6}-204.372 \times 10^{6}\right) \geq \lambda \\
\left(Z_{2}-104.400 \times 10^{6}\right) /\left(348 \times 10^{6}-104.400 \times 10^{6}\right) \geq \lambda
\end{gathered}
$$

and all other original constraint in the model; $\lambda \geq 0$. The solution of MOFLP is presented in Table 3 . The compromised solution yields the level of satisfaction $(\lambda)=0.533$ for maximizing the releases for irrigation and power simultaneously by satisfying the constraint of the system under consideration. The compromised solution provides the optimal releases, i.e. $\mathrm{RI}=348.670 \mathrm{Mm}^{3}$ and $\mathrm{RP}=234.285 \mathrm{Mm}^{3}$ respectively.

\section{Conclusions}

The objective of the study is to develop the MOFLP models for optimal cropping pattern that maximizes Net Benefits, Crop Production, Employment Generation and Manure Utilization simultaneously and also for maximization of releases for irrigation and power for optimal operation of the reservoir. To achieve this, max-min approach based MOFLP models have been developed and applied to Jayakwadi Project Stage II, Maharashtra State, India.

The observations from the present study are as given below:

- This study proposes a basis for irrigation planning as an integrated approach.

- The level of satisfaction for a compromised solution for four conflicting objectives under fuzzy environment is works out to be $\lambda=0.680$. The MOFLP compromised solution provides NB $=1088.46$ Million Rupees, $\mathrm{CP}=241003$ Tons, $\mathrm{EG}=23.13$ Million Man days and MU = 111454.70 Tons respectively and irrigation intensity is $79.40 \%$.

- The results of the application of MOFLP model for reservoir operation indicate that the maximum level of satisfaction $(\lambda)$ is 0.533 achieved by maximizing both the objectives simultaneously and the corresponding values of RI and RP are $348.670 \mathrm{Mm}^{3}$ and $234.285 \mathrm{Mm}^{3}$ respectively.

- The present model will be helpful for the decision maker to take decisions under conflicting situations when planning for different objectives simultaneously.

- The developed models are capable to trace out an integrated irrigation planning with prime consideration for economic, social and environmental issues.

- The results obtained under the present study are sensitive to the changes in the market price of the crop, cost of crop production, unit labour cost, and unit manure cost and water availability.

\section{Acknowledgements}

The author is thankful to the Director, BCUD of Savitribai Phule Pune University, Pune State of Maharashtra, India for permission to take up this study at Amrutvahini College of Engineering, Sangamner and for providing all the necessary facilities and research grant for carrying out the research work. The author would like to express sincere thanks to Command Area Development Authority, Aurangabad, Maharashtra State, India and Mahatma Phule Krishi Vidyapeeth Rahuri, Ahmednagar, Maharashtra State, India for providing necessary data for analysis.

\section{References}

[1] Raju, K.S. and Nagesh Kumar, D. (2000) Optimum Cropping Pattern for Sri Ram Sagar Project: A Linear Programming Approach. Journal of Applied Hydrology, XIII, 57-67. 
[2] Raju, K.S. and Nagesh Kumar, D. (2000) Irrigation Planning of Sri Ram Sagar Project Using Multi Objective Fuzzy Linear Programming. ISH Journal of Hydraulic Engineering, 6, 55-63. http://dx.doi.org/10.1080/09715010.2000.10514665

[3] Raju, K.S. and Duckstein, L. (2003) Multiobjective Fuzzy Linear Programming for Sustainable Irrigation Planning: An Indian Case Study. Soft Computing, 7, 412-418. http://dx.doi.org/10.1007/s00500-002-0230-6

[4] Regulwar, D.G. and Anand Raj, P. (2008) Development of 3-D Optimal Surface for Operation Policies of a Multireservoir in Fuzzy Environment Using Genetic Algorithm for River Basin Development and Management. Water Resources Management, 22, 595-610. http://dx.doi.org/10.1007/s11269-007-9180-1

[5] Regulwar, D.G. and Kamodkar, R.U. (2010) Derivation of Multipurpose Single Reservoir Release Policies with Fuzzy Constraints. Journal of Water Resource and Protection, 2, 1030-1041. http://dx.doi.org/10.4236/jwarp.2010.212123

[6] Regulwar, D.G. and Gurav, J.B. (2010) Fuzzy Approach Based Management Model for Irrigation Planning. Journal of Water Resource and Protection, 2, 545-554. http://dx.doi.org/10.4236/jwarp.2010.26062

[7] Regulwar, D.G. and Gurav, J.B. (2011) Irrigation Planning under Uncertainty-A Multi Objective Fuzzy Linear Programming Approach. Water Resources Management, 25, 1387-1416. http://dx.doi.org/10.1007/s11269-010-9750-5

[8] Regulwar, D.G. and Gurav, J.B. (2012) Sustainable Irrigation Planning with Imprecise Parameters under Fuzzy Environment. Water Resources Management, 26, 3871-3892. http://dx.doi.org/10.1007/s11269-012-0109-y

[9] Regulwar, D.G. and Gurav, J.B. (2013) Two-Phase Multiobjective Fuzzy Linear Programming Approach for Sustainable Irrigation Planning. Journal of Water Resource and Protection, 5, 642-651. http://dx.doi.org/10.4236/jwarp.2013.56065

[10] Regulwar, D.G. and Gurav, J.B. (2014) Irrigation Planning with Fuzzy Parameters-An Interactive Approach. Journal of Agricultural Science and Technology, 16, 1157-1172.

[11] Gurav, J.B. and Regulwar, D.G. (2011) Minimization of Cost of Cultivation along with Interactive Decision Making under Fuzzy Environment. ISH Journal of Hydraulic Engineering, 17, 30-42. http://dx.doi.org/10.1080/09715010.2011.10515043

[12] Gurav, J.B. and Regulwar, D.G. (2012) Multi Objective Sustainable Irrigation Planning with Decision Parameters and Decision Variables Fuzzy in Nature. Water Resources Management, 26, 3005-3021. http://dx.doi.org/10.1007/s11269-012-0062-9

[13] Kamodkar, R.U. and Regulwar, D.G. (2010) Modelling Multiobjective Reservoir Operation in Uncertain Parameter Environment. Journal of Indian Water Works Association, 8, 27-35.

[14] Kamodkar, R.U. and Regulwar, D.G. (2010) Multipurpose Single Reservoir Operation with Fuzzy Technological Constraints. ISH Journal of Hydraulic Engineering, 16, 49-63. http://dx.doi.org/10.1080/09715010.2010.10515015

[15] Kamodkar, R.U. and Regulwar, D.G. (2014) Optimal Multiobjective Reservoir Operation with Fuzzy Decision Variables and Resources: A Compromise Approach. Journal of Hydro-Environment Research, 8, 428-440. http://dx.doi.org/10.1016/j.jher.2014.09.001

[16] The Report of Commissionerate of Agriculture, Maharashtra State (2006) Agricultural Statistical Information Part-II, Maharashtra State, India, Part-II: 1-255.

[17] Klir, G.J. and Yuan, B. (2007) Fuzzy Sets and Fuzzy Logic: Theory and Applications. Prentice Hall of India Private Ltd, New Delhi. 